\title{
Chinese-English and Its Linguistic Features
}

\author{
WEI Shen-yi \\ Zhoukou Normal University, Zhoukou, China
}

\begin{abstract}
English globalization has actually triggered the localization of the English language, so Chinese-English is a fact not a hypothesis. This paper mainly discusses the origin of Chinese-English and tries to explore the essential features of it through the theories of language migration and analysis of many examples. This paper points out, based on Standard English, Chinese-English is an English variety mainly used by the Chinese people. It is unavoidable, useful, and necessary to spread Chinese culture. Chinese-English and Chinglish are inter-language variants because Chinese cultural influences are different. Chinese-English has its own complete system, regularity, and stability. This paper further clarifies the position of the Chinese-English and treats the Chinese-English phenomenon dialecticly and scientifically.
\end{abstract}

Keywords: Chinese-English, Chinglish, linguistic features

\section{Introduction}

With the further opening-up and exchanges between China and the international world, more and more Chinese are participating in English learning. China now has the largest English learning community in the world. There are more than 300 million English learners in China. Todd's study shows that as many as two billion people are now capable of using English in different degrees in the world (Todd, 2005), and non-native speakers comprise more than two thirds of English potential speakers, heavily outnumbering the native speakers (Todd, 2006). Some experts at the Second International Conference on Foreign Language Teaching Methodology at Shanghai International Studies University reveal that the total number of English learners in China will exceed the whole population of English speaking countries in the near future (HU, 2008). This study was conducted in 2005. The existence of Chinese-English is a fact, not a hypothesis, with a vast range of prospects. As people know, language used by a large amount of people may hold more influence, so it is of realistic value to study China-English.

English globalization has actually triggered the localization of the English language, because each nation possesses a different history, culture, and political environment. Thus, English, as a tool for international communication, is destined to be branded with different national colors. The wide use of English among non-native speakers in a diverse range of social and cultural contexts will inevitably produce regional varieties. Under the influence of globalization, the Chinese people need to express what is unique in China in intercultural communication. Chinese culture has made it necessary to use Chinese-English to express Chinese ideas as part of one's communicative competence. Therefore, a comprehensive study of Chinese-English is greatly valued in

WEI Shen-yi, associate professor, master, The Foreign Languages School, Zhoukou Normal University. 
language theory and in communicative practice as well. However, many English learners regard Chinese-English as distorted language, hence, they totally ignore different features of Chinese culture. It is evident that besides English in the UK and English in the US, there exist other forms, like Singaporean English in Singapore, Indian-English in India, and so does Chinese-English in China.

Chinese-English is different from Chinglish, which is not accepted by foreigners. It is not the standard way of using English. It refers to the English usually created by the beginning Chinese-English-learners who translate English into their own words so arbitrarily. It is a language interfered with by the Chinese language, and does not accord with the culture habits of English. It deviates from normal English more or less, and destroys communication, influence, and the quality of conversation. Language contact of English and Chinese can be traced back to the 17th century, and since then, the English language has been experiencing a long process of localization in China. However, it was not until 1982 that the term China-English was first proposed by GE Chuan-gui, a well-known Chinese lexicographer. A lot of Chinese words permeate into English vocabulary, becoming a major resource of English vocabulary. To some extent, English turns into a linguistic framework. According to the book World English (2002, p. 110), Chinese-English has devoted 5\%-20\% of the vocabulary of the newly created English words, surpassing any other resource to enlarging English vocabulary since 1994. These words and phrases are all understandable for native speakers without any specific explanation, for example, "long time no see" and "Paper Tiger".

\section{The Definition of Chinese-English}

The three concentric circles theory raised by B. B. Kachru (1982) is generally recognized by international English field. It carves up different English-speaking regions according to development of world English and sociolinguistics, including inner circle, outer circle, and extended circle. The inner circle embodies countries with Anglo-Saxon culture, such as Britain, United States, Canada, Australia, New Zealand, and Ireland. The outer circle comprises countries adopting English as their official language or one of official languages, or paralanguage and second language, such as India, Malaysia, Singapore, Nigeria, Kenya, and South African nations (mainly former British colonies). Countries in the extended circle take English as the international communication tool and extensively use English in international events such as political activities, business negotiation, and cultural exchange. Nowadays, people in Russia, Japan, China, and Egypt have got more and more enthusiasm at learning English, and the governments also pay every-increasing attention to the English education. To meet the needs of international communication, those countries and regions have a tendency for wider use of English. The relation and transformation among "inner circle”, "outer circle”, and "extended circle” boost the combination of the globalization and localization of English.

With the development of social language and international culture, Chinese-English is inevitable. A number of scholars have proposed their definitions of Chinese-English from their particular perspectives. WANG Rong-pei (1991) holds that the definition of Chinese-English should cover the following three points: (1) Chinese-English is used by the Chinese people; (2) Chinese-English has Standard English as its core; and (3) Chinese-English has Chinese features. JIA Yu-xin (2000) makes his contribution to Chinese-English: Chinese-English is an English variety used by Chinese people in cross-cultural communication; its modification is caused by the Chinese language, the ways of Chinese culture. Chinese-English is based on normative English 
and is capable of entering the English language, for example, the following words: tea, kowtow, and Great Leap Forward. Also JIANG Yu-jun (1995) states that Chinese-English is an English variety used by the Chinese people and is based on Standard English having Chinese characteristics, which are unavoidable and useful in spreading Chinese culture.

From the various definitions of Chinese-English, one can summarize some of the properties of Chinese-English.

First, Chinese-English is English used by the Chinese. "The Linguistic and Cultural Identities of Chinese-English and the Application in China” refers to the Chinese people who have grown up in China's social and cultural background and communicate with the English speaking people.

Second, it is based on Standard English, that is, it is in accord with the grammar of Standard English.

Third, it is an international variety of English affected by Chinese culture.

Chinese-English has normative English as its core. In the process of understanding Chinese culture, people from foreign countries accept specific qualities of China gradually. "According to normal English, Chinese-English expresses specific objects about China’s social culture in many fields” (HU, 2008, p. 36). To keep pace with the world, China communicates with other countries in many fields. Chinese-English contributes to the international communication, to the spreading of Chinese culture. Chinese-English is mainly used as an international language in China, with the unique, nasalized words or phrases of Chinese. Chinese-English is understood as a standardized variety in English use in China, which reflects Chinese cultural norms and concepts. Chinese-English is the result of cultural exchanges, collisions and the mixing together of Chinese and Western Cultures. It is the result of languages influence, infiltration, and development.

\section{The Difference Between Chinese-English and Chinglish}

Chinese-English is different from Chinglish, which is inauthentic in oral and written expression. It does not accord with the grammar rules and habits of the English language. The ways of thinking, expression of Chinglish and selecting words are Chinese-style. It is the result of hidebound translation and literal translation. Chinglish is nonstandard, obscure, and easy to misunderstand. Chinese-English and Chinglish are interrelated in some aspects: Both of them express Chinese things with Chinese features. Chinese-English and Chinglish exist side by side. Yet there is an essential distinction between them: Chinese-English is normative English and a member of world English; Chinese-English, with its increasing understanding in the world, will exert a great influence on the English language. Because people live in different environments and have different ways of thinking, cultures, local conditions and customs are reasonably different. Chinese-English appears in order to express the unique values of China. Some expressions are widely used and spread through international association. However, Chinglish is a deformed language with unstable composition and narrow use; it can cause barriers in China's international communication and the spreading of culture.

If Chinese-English is used properly, it can more faithfully reflect the original text, especially in expressing something unique to China. It is an excellent example in expressing China's unique culture that the famous Chinese novel Hong Lou Meng is translated into A Dream of Red Mansions.

To sum up, Chinese-English and Chinglish are both related and distinguishable. On one hand, both of them have put across something unique to China, have Chinese features. On the other hand, with a new vocabulary and 
structure, Chinese-English is normative English and will increase its strength with further publicity to the world. In general, Chinese-English is based on Standard English and shares idiomatic usage of world English. It helps to spread China's unique culture such as words, phrases, syntax, cognitive style, figures of speech, literary style, and discourse structure. While Chinglish is improper use of English due to poor knowledge of the English language and culture, it shall accordingly hinder communication with other cultures. In the future, Chinglish will probably diminish or even disappear with the deepening of cultural communication between China and other countries.

\section{The Features of Chinese-English}

Chinese-English is used to express something unique about China with an English variant. It is the product of endemic social culture, and, also, is an international English-using variant. Chinese-English has its own characteristics.

\section{Lexical Features}

In order to express or describe something unique about China, the providers who use Chinese-English create new means of words or phrases with Chinese characteristics through transliteration and semantic regeneration, such as, jiaozi, wonton, kowtow, kongfu, toufu, mahjong, litchi. The lexical features of Chinese-English are mainly shown in these Chinese borrowings. Taking Standard English as its core, the English language enriches itself by absorbing borrowed words from Chinese culture. After China's reforms and opening-up, the total number of borrowings in English increased rapidly. These Chinese phrases in English are translated by means of word-by-word translation. Below are some examples of Chinese history and culture: Confucianism, Five Classics, paper tiger, Great Leap Forward, Cultural Revolution, Gang of Four, Chinese herbal medicine, One China Policy, iron rice bowl, open-door policy, floating population, laid-off workers, Four Modernizations, vegetable basket project, emancipate the mind and seek truth from facts, special economic zone, reform and opening-up program, one country two systems, the cause of building socialism with Chinese characteristics, etc. And there are some idiomatic expressions accepted by English and American people, for example, Chinese people often say "long time no see" when they meet each other. Originally, this was a Pidgin English, but now it is uttered by many native English speakers.

\section{Syntactic Features}

Due to the influence of thought and Chinese syntactic characters, Chinese-English tends to prepose modifiers so that there are many short simple sentences. In Chinese-English writings and promotional materials, Chinese writing characteristics and texts structures are inevitable. The main difference in sentence structure between English and Chinese is that English is a language of hypo-taxis, while Chinese is a language of parataxis. "Hypo-taxis" refers to sentences that are organized by grammatical relations; "parataxis" means that sentences are structured by the logical relations. Therefore, English sentences are well-knitted, and Chinese ones are terse and lucid. Some shortened sentence forms are adapted in Chinese so as to make sentences concise (JIANG, 1995). Consequently, this feature of Chinese sentence is reflected in Chinese-English consisting of many short sentences forms. Examples (1)-(3) illustrate this:

Example (1) Safety is first and prevention is most important.

Example (2) Life is above and service is first. 
Example (3) Ten thousand years are too long, seize the day and seize the hour.

\section{Discourse Features}

At present, the study of Chinese-English at the discourse level is the weakest among the linguistic aspects of Chinese-English (DU \& JIANG, 2010). Though the analysis and the description of discourse features are complex, Chinese experts and scholars have never given up their attempts to explore Chinese-English in this field. ZHAO Yan-ping (2001) investigated the features of the thinking model about Chinese students majoring in English, and they make this conclusion: Chinese students are likely to use the "general-particular pattern" and their dominant thinking is "the problem-solution pattern" with a "hidden” feature. They do not start a narration with a subject but make a hint at other thing. HU Wen-zhong (2008) concluded from his research of English language proficiency of Chinese students at the University of Kansas that English writing by Chinese students is obviously influenced by their mother tongue no matter what their English proficiency is. XIE Zhi-jun (2003) held that Chinese-English should have its own discourse patterns and styles. His study confirms the hypothesis of cultural thought patterns initially proposed by Robber Kaplan as early as in 1966. According to Kaplan, the rhetorical pattern in English expositions is a linear type, while the rhetorical pattern in Chinese expositions is a spiral type. It is a tendency for the modifiers to be placed in the frontal position of a sentence in Chinese-English. So there are many simple sentences in Chinese-English. ZHANG Wen-xia (2002) described and analysed the evaluation on the textural paragraph and confirmed that the discourse features of Chinese-English are caused by Chinese influences.

This research shows that the discourse of Chinese-English is under the influence of Chinese cultures, mixed with Chinese mode of thinking. Chinese-English is evolved from two sources: (1) native speakers' description/accounts of Chinese society and culture; (2) the Chinese accounts of themselves and the world in English, an English variety that is saturated with Chinese culture. The characteristics of the Chinese-English are unavoidable mainly because of the ways of Chinese thinking and traditional Chinese culture. This shows that "one's accomplishment of the language acquisition marks the formation of one's thinking model” (JIANG, 1995, pp. 50-55). Therefore, the ways of Chinese thinking must have a great influence on learning another way of thinking, so the Chinese characteristics inevitably exist in the English expressions created by the Chinese people.

\section{Conclusion}

English, as an international language, has become an indispensable tool for Chinese people to communicate with the world. Chinese-English exists objectively. Along with the rejuvenation of China, the output of Chinese culture is becoming more and more important. Chinese-English, as a tool of recent history, culture, and the politics of modern China, plays an important role. Although Chinese-English is not enough to become a national variety, it is the absolutely necessary for the English-speaking world supplementing Standard English. Chinglish is the result of ignoring or misunderstanding of British culture and customs, hence, Chinese-English is not equal to Chinglish, so it is necessary to get rid of Chinglish in writing. Chinese-English creates some new means of words and phrases with Chinese characteristics through transliteration and semantic regeneration. English writing usually follows the mode of Hypo-taxis, while the Chinese-English often follows the mode of parataxis. As to the rhetorical pattern, Chinese-English expositions are a spiral type. Under the influence of globalization, the Chinese need to express what is unique in China in intercultural communication. Chinese culture has made it 
necessary to use Chinese-English to express Chinese ideas as part of one's communicative competence. Therefore, a comprehensive study of Chinese-English is greatly valued in language theory and in communicative practice, as well. Chinese-English is unavoidable and useful in spreading Chinese culture.

\section{References}

Barber, C. L. (1972). The story of language. Oxford: Oxford University Press.

Brutt Grifler, J. (2002). World English: A study of its development. Clevedon: Multilingual Matters Ltd..

Cannon, G. (1998). Chinese borrowing in English. American Speech, 12, 37-40.

DU, R. Q., \& JIANG, Y. J. (2010). English as a Chinese language. English Today, 6, 33-36.

GE, C. G. (1982). On China English. Foreign Language and Teaching, 11, 39-43.

HU, W. Z. (2008). Culture and communication. Beijing: Foreign Language Teaching and Research Press.

JIA, Y. X. (2000). Intercultural communication. Shanghai: Shanghai Foreign Language Education Press.

JIANG, Y. J. (1995). Chinglish and China English. English Today, 12, 50-55.

Kachru, B. B. (1982). The other tongue. Chicago, Illinois: University of Illinois Press.

Kaplan, R. (1966). Writing expertise and second language proficiency. Language Learning, 39, 136-141.

Todd, L. (2005). Tracking the homing Pidgin: A millennium report. English Today, 8, 25-27.

Todd, L. (2006). International English usage. New York: New York University Press.

WANG, R. P. (1991). The existence of China-English. Foreign Language and Teaching, 6, 40-45.

XIE, Z. J. (2003). On communication. Shanghai: Shanghai Foreign Language Education Press.

ZHANG, W. X. (2002). Using English in China. English Today, 9, 30-36.

ZHAO, Y. P. (2001). Culture and communication. Beijing: China People University Press. 